\title{
Treatments for Adult Obstructive Sleep Apnea
}

\author{
Ji Ho Choi, MD, PhD \\ Department of Otorhinolaryngology-Head and Neck Surgery, Soonchunhyang University College of Medicine, Bucheon Hospital, Bucheon, Korea
}

\begin{abstract}
Obstructive sleep apnea (OSA) is a chronic sleep disorder that requires a long-term multidisciplinary approach. OSA is characterized by repetitive upper airway collapses during sleep, resulting in various symptoms and outcomes. Therefore, accurate diagnosis and appropriate treatment are needed. In general, positive airway pressure (PAP), oral appliance (OA), and surgery are considered as the primary therapeutic methods, and weight loss and positional therapy are additional or adjunctive treatment options. PAP is recommended for the standard treatment of moderate-to-severe OSA [apnea-hypopnea index $(\mathrm{AHI}) \geq 15$ ] and is the optional treatment for mild OSA (5 $\leq$ $\mathrm{AHI}<15)$. OA is indicated in mild-to-moderate OSA $(5 \leq \mathrm{AHI}<30)$ that favors OA over PAP. Surgical treatment is usually recommended for patients who manifest anatomical defects that can be alleviated surgically or show a high degree of surgical success rate. Surgery is also indicated in cases refractory to or contraindicated for medical treatments such as PAP and OA. In addition, surgical therapy may be performed as adjunct treatments along with other therapies. Diverse therapeutic options including the indications, mechanisms of action, clinical effects, and limitations should be discussed with the patient during the counseling sessions. Furthermore, the patients should actively participate in the treatment of their own disorder. In summary, an individualized therapeutic method should be considered based on a comprehensive analysis of the patient's physical findings, such as upper airway anatomy, and obesity, results of polysomnography, such as AHI, respiratory disturbance index, and minimum oxygen saturation, in addition to therapeutic preferences and expectations.

Sleep Med Res 2021;12(1):9-14
\end{abstract}

Key Words Obstructive sleep apnea, Therapy, Positive airway pressure, Oral appliance, Surgery.

Received: April 13, 2021

Accepted: May 9, 2021

Correspondence

Ji Ho Choi, MD, PhD

Department of Otorhinolaryngology-

Head and Neck Surgery,

Soonchunhyang University College of Medicine,

Bucheon Hospital, 170 Jomaru-ro,

Bucheon 14584, Korea

Tel +82-32-621-5015

Fax +82-32-621-5016

E-mail handsomemd@hanmail.net

ORCID

Ji Ho Choi

https://orcid.org/0000-0002-5194-930X

(a) This is an Open Access article distributed under the terms of the Creative Commons Attribution Non-Commercial License (https://creativecommons.org/licenses/by-nc/4.0) which permits unrestricted non-commercial use, distribution, and reproduction in any medium, provided the original work is properly cited.

\section{INTRODUCTION}

Obstructive sleep apnea (OSA) in adults should be evaluated as a chronic disease that needs long-term and comprehensive care [1]. OSA is characterized by repeated events of complete or partial upper airway collapse during sleep [2].

The symptoms and signs of OSA are numerous, including habitual snoring, observed apnea, morning headache, excessive daytime sleepiness, fatigue, memory loss, and decreased libido, etc. [3]. OSA should be diagnosed accurately based on history, physical examination, upper airway evaluation, for example, using imaging tests and drug-induced sleep endoscopy, and polysomnography [4]. Untreated OSA increases the risk of serious complications, such as hypertension, myocardial infarction, angina, arrhythmia, stroke, type 2 diabetes, and decreased sexual function [5-7]. Therefore, patients diagnosed with OSA require prompt and effective treatment.

The therapeutic modalities for OSA include positive airway pressure (PAP), oral appliance (OA), surgery, weight loss, and positional therapy. PAP, OA, and surgery are considered primary treatments, and weight loss and positional therapy represent adjunctive treatments $[1,8]$. There is no single treatment that addresses the challenges of all OSA patients at once. Since the indications, effects, advantages, and disadvantages associated with each therapeutic method differ, appropriate customized management is essential for each patient [9-11]. In order to determine the therapeutic option appropriate for each patient, the patient's physical findings, polysomno- 
graphic outcomes, and opinion should be considered comprehensively $[1,8]$. It is not necessary to insist on the first or single treatment method alone. If the first therapeutic option is ineffective or fails, another management option can be applied. In addition, two or more treatments may be combined for successful management.

This article will review the features of various therapeutic methods including indications, mechanisms of action, clinical effects, and limitations and will provide useful insight into the therapeutic principles for OSA.

\section{THERAPEUTIC METHODS}

\section{Positive Airway Pressure}

PAP is primarily recommended for the treatment of moderate-to-severe OSA [apnea-hypopnea index $(\mathrm{AHI}) \geq 15][1,12,13]$. PAP is also optionally indicated for the management of mild OSA $(5 \leq \mathrm{AHI}<15)[1,12,13]$. Therefore, PAP represents a substantial treatment of choice for all types of OSA regardless of the severity of AHI. PAP supplies pneumatic splint to maintain the patency of the upper airway in patients with OSA and as pressure increases, the upper airway tends to enlarge $[14,15]$. PAP therapy has various positive effects clinically [16]. Based on high-level evidence-based studies, PAP treatment effectively decreases AHI and improves subjective and objective measures of excessive daytime sleepiness [16,17]. In addition, PAP therapy improved quality of life and decreased high blood pressure in low-level evidencebased studies $[16,18,19]$. According to the recent the American Academy of Sleep Medicine clinical practice guideline for PAP, PAP is recommended for the management of adult OSA with excessive daytime sleepiness [20]. PAP is also suggested for the treatment of adult OSA with decreased sleep-related quality of life or comorbid hypertension [20]. Moreover, PAP is effective in reducing the risk of various adverse events including motor vehicle accidents [21]. However, PAP is inconvenient and associated with side effects such as unintentional mask removal, pressure intolerance, air or oral leakage, skin injury, nasal obstruction, rhinorrhea, nasal bleeding, and aerophagia $[1,16,22,23]$. Consequently, these adverse effects can lead to decreased PAP compliance.

\section{Oral Appliance}

$\mathrm{OA}$ is recommended for the management of mild-to-moderate OSA $(5 \leq \mathrm{AHI}<30)$ in patients who prefer OA over PAP or for those who are intolerant or refractory to other treatments including PAP, positional therapy, and weight loss [1,24-27]. In addition, $\mathrm{OA}$ is indicated for the reduction of simple snoring that cannot be managed by other therapies such as change of sleep position or weight control $[1,27]$. OA increases the patency of upper airway during sleep in OSA patients via the following mechanisms: 1) expansion of the upper airway and/or; 2) diminished upper airway collapse or increased upper airway muscle tone
$[1,28]$. According to numerous studies (mostly low-level evidencebased studies), OA therapy significantly improves AHI in OSA that is usually not severe and alleviates various clinical symptoms and signs including excessive daytime sleepiness [28-31]. In addition, OA treatment has beneficial but weak effects on daytime systolic and diastolic blood pressure and decreases daytime heart rate compared with inactive or placebo methods [32,33]. OA has several limitations such as dental-related side effects and discomfort. Side effects associated with OA usage include excessive salivation, dry mouth, tooth and myofascial pain, gum irritation, temporomandibular joint disorder, dental misalignment, and occlusal change $[1,27,28,34]$. These limitations can reduce the compliance with $\mathrm{OA}$.

\section{Surgery}

There are three indications for the surgical treatment of OSA. The primary indication for surgery in patients with OSA is an obvious obstructive abnormality of the upper airway that can be improved surgically or a high probability of successful surgical outcomes, such as surgery for severe obstructing upper airway mass, and tonsillectomy for large tonsils $[1,8]$. Second or alternative indication involves cases who are contraindicated for nonsurgical therapies including PAP or OA $[1,8]$. Third, surgery is indicated as an adjunctive treatment to increase tolerance of other OSA therapies, for example, nasal surgery to improve PAP or OA compliance due to nasal obstruction [1]. Most surgeries improve OSA via mechanisms that surgically modify or reconstruct the upper airway anatomy to enlarge the space and/or increase muscle tension $[1,8,35]$. OSA-related surgeries consist of the following: nasal surgeries, such as septoplasty, turbinate surgery, nasal polypectomy or tumor removal, and endoscopic sinus surgery; nasopharyngeal surgeries, such as adenoidectomy and nasopharyngeal tumor removal; oral and oropharyngeal surgeries, such as uvulopalatopharyngoplasty (UPPP) and modifications, tonsillectomy, and palatal implants; hypopharyngeal surgeries, such as tongue base reduction, lingual tonsillectomy, genioglossus advancement, hyoid suspension, and epiglottoplasty; laryngeal surgeries, such as laryngeal polypectomy or tumor removal; and multi-level or other surgeries, such as oropharyngeal and hypopharyngeal surgery, maxillomandibular advancement, tracheotomy, and bariatric surgery $[1,8,35,36]$. Nasal surgery plays several important roles in OSA patients. According to a recent metaanalysis, isolated nasal surgery appears to decrease AHI, but only with minimal significance [37]. In addition, it is associated with reduction of subjective and objective signs and symptoms of snoring, improvement of excessive daytime sleepiness, a decrease of therapeutic pressure in PAP users, and increased PAP compliance [38-40]. UPPP is generally one of the most common surgical procedures in patients with OSA. UPPP is not associated with a high rate of surgical success when performed randomly, whereas it increases the surgical success rate when performed selectively based on anatomical staging $[41,42]$. Multi-level surgery is asso- 
ciated with a higher surgical success rate than the single-level surgery when two or more obstruction sites are suspected [43]. Transoral robotic surgery for base of tongue reduction is mostly performed via palatal surgery, and the results are comparable to those of multi-level surgery [44]. Maxillomandibular advancement is a surgical procedure that extends the retropalatal and retrolingual airway by advancing the maxilla and mandible simultaneously, reducing AHI comparable to PAP in most patients $[45,46]$. Hypoglossal nerve stimulation is a recently developed surgical management procedure using an implanted neurostimulation system that increases upper airway muscle tone to prevent the collapse of the pharynx and decreases AHI moderately $[47,48]$. Surgery may yield diverse clinical outcomes including symptoms and signs, quality of life, cardiovascular risk, motor vehicle accidents, and mortality [49-51]. However, surgical limitations include uncertainty in predicting surgical success, surgical risks, and complications, such as foreign body sensation, dryness, velopharyngeal incompetence, speech alterations, and swallowing abnormalities $[1,8,52,53]$.

\section{Weight Loss}

Weight loss is recommended for the treatment of all overweight or obese OSA patients $[1,8,54]$. Weight loss should be combined with a primary treatment such as PAP, OA, and surgery $[1,54]$. Obesity increases the volume of upper airway soft tissue, narrowing the upper airway, and the upper airway fat deposition increases the collapsibility, resulting in OSA with worsening outcomes [55]. Successful weight reduction via dietary management may alleviate AHI in patients with obese OSA $[1,54]$. According to a longitudinal study, a weight gain of $5 \%, 10 \%$, or $20 \%$ may lead to an approximate increase of $15 \%, 32 \%$, or $70 \%$ in AHI, respectively [56]. However, a weight loss of $5 \%, 10 \%$, and $20 \%$ is expected to result in approximately $14 \%, 26 \%$, and $48 \%$ reduction in AHI, respectively [56]. Weight loss has several limitations including the reduced success rate of dietary control, and the low cure rate by dietary restriction alone [1,54]. Bariatric surgery is indicated for the management of obese patients who carry a body mass index $(\mathrm{BMI}) \geq 40 \mathrm{~kg} / \mathrm{m}^{2}$ or a BMI $\geq 35 \mathrm{~kg} / \mathrm{m}^{2}$ with significant obesity-related co-morbidities, such as hypertension, type II diabetes, lipid abnormalities, non-alcoholic fatty liver disease, and osteoarthritis, and have been resistant to treatment via dietary weight loss [57]. Bariatric surgery should also be considered as a minimally invasive therapy for use as an adjunct therapy to active and first-line interventions such as PAP [1,54].

\section{Positional Therapy}

Positional therapy is recommended for the management of patients with OSA exhibiting AHI that is more than double in the supine position compared with the non-supine sleep position $[1,54,58]$. Positional therapy can be used as an adjunct to primary treatment in OSA patients and performed using a positioning device, such as alarm, ball, pillow, vest, or vibrator $[1,54,59,60]$.
Positional therapy improves OSA by avoiding the supine position: the upper airway soft tissue including soft palate and tongue are placed inferiorly under the effect of gravity, leading to a decrease in the upper airway size or patency and resulting in increased respiratory disturbances such as apnea or hypopnea during sleep [58,59]. According to the related meta-analysis of 21 papers, positional therapy significantly improves AHI by $54.1 \%$ and the lowest oxygen saturation by $3.3 \%$, whereas it does not significantly affect arousal index or sleep efficiency [60]. Positional therapy is associated with several limitations. It is basically difficult to maintain a patient in one position (non-supine position) during sleep without side effects [1,54]. A few established or standardized positional therapeutic devices have been used with objective monitoring $[1,54]$. Further, positional therapy does not normalize AHI in all OSA patients [1,54].

\section{THERAPEUTIC PRINCIPLES}

There are three important points to consider when treating adult OSA $[1,8]$. First, OSA is considered a chronic disease requiring prolonged and multidisciplinary approach to management such as hypertension, diabetes, and allergic disease. Second, the patients should be actively involved in determining and contributing to their therapeutic options. Third, the most appropriate OSA therapy should be based on the patient's physical findings, such as upper airway anatomy and obesity, in addition to the results of polysomnography such as AHI, respiratory disturbance index (RDI), and minimum oxygen saturation, along with the patient's therapy preferences and expectations. The therapeutic principles for OSA are summarized in Fig. 1.

\section{Patient's Physical Findings (Anatomy)}

Before deciding the treatment approach, the patient's physical findings should be evaluated [1]. Physical findings include general appearance such as obesity, and increased neck circumference; nasal cavity, such as deviated nasal septum, hypertrophied turbinate, and nasal polyp or tumor; features of nasopharynx, such as adenoid vegetation and nasopharyngeal tumor; characteristics of oral cavity and oropharynx, such as high arched palate, large soft palate, elongated uvula, hypertrophied palatine tonsil, and macroglossia; hypopharynx, including hypertrophied lingual tonsil, omega-shaped epiglottis, hypopharyngeal tumor, micrognathia, and retrognathia; and larynx, including paralyzed vocal cords and laryngeal polyps or tumors $[61,62]$.

\section{Patient's Polysomnography}

Important polysomnographic parameters that are useful in determining the treatment method include sleep data, including the total recording time, total sleep time, sleep efficiency, sleep latency, wake after sleep onset, and sleep stages; arousal parameters, such as arousal index, respiratory arousal index, and spontaneous 


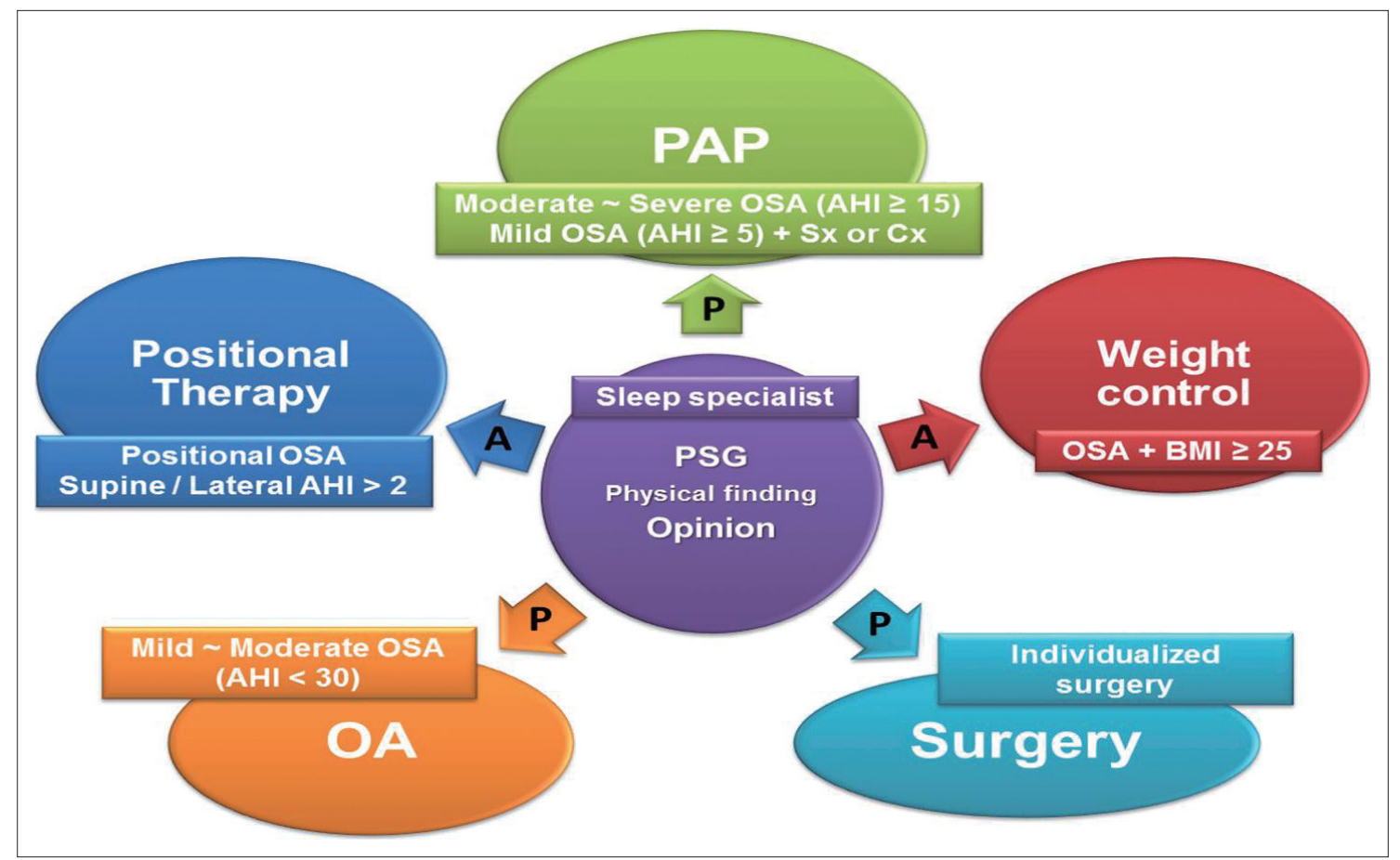

Fig. 1. Therapeutic principles underlying OSA. PAP: positive airway pressure, OA: oral appliance, OSA: obstructive sleep apnea, AHI: apnea-hypopnea index, Sx: symptoms, Cx: complications, BMI: body mass index, P: primary treatment, A: adjunctive treatment, PSG: polysomnography.

arousal index; respiratory parameters, such as $\mathrm{AHI}, \mathrm{RDI}$, oxygen desaturation index $\geq 3 \%$ or $4 \%$, mean oxygen saturation, minimum oxygen saturation, and snoring; cardiac parameters such as average heart rate during sleep, highest heart rate during sleep, bradycardia, and tachycardia; and movement-related parameters, such as periodic limb movements of sleep (PLMS) index and PLMS arousal index [63].

\section{Patient's Opinion}

The outcomes of physical examination and polysomnography are explained to the patient. The sleep specialist also explains an individualized natural course of disorder, risk or aggravating factors, risk factor modification, and possible consequences $[1,8]$. In addition, various OSA therapies including the indications, mechanisms of action, clinical effects, and limitations associated with each method should be counseled $[1,8]$. Further, the patients should actively participate in the management of their disorder, expressing their opinions including therapeutic expectations and preferences $[1,8]$.

\section{CONCLUSION}

Personalized therapeutic options should be considered systematically according to the patients' physical findings, including upper airway structure and obesity; polysomnographic outcomes, such as AHI, RDI, and minimum oxygen saturation; and therapeutic preferences and expectations.

\section{Acknowledgments}

This study was supported by the Soonchunhyang University Research Fund.

\section{Conflicts of Interest}

The author has no financial conflicts of interest.

\section{REFERENCES}

1. Epstein LJ, Kristo D, Strollo PJ Jr, Friedman N, Malhotra A, Patil SP, et al. Clinical guideline for the evaluation, management and long-term care of obstructive sleep apnea in adults. J Clin Sleep Med 2009;5:26376.

2. Guilleminault C, Tilkian A, Dement WC. The sleep apnea syndromes. Annu Rev Med 1976;27:465-84.

3. Young T, Palta M, Dempsey J, Skatrud J, Weber S, Badr S. The occurrence of sleep-disordered breathing among middle-aged adults. N Engl J Med 1993;328:1230-5.

4. American Academy of Sleep Medicine. International classification of sleep disorders. 3rd ed. Darien, CT: American Academy of Sleep Medicine 2014.

5. Caples SM, Garcia-Touchard A, Somers VK. Sleep-disordered breathing and cardiovascular risk. Sleep 2007;30:291-303.

6. Gaines J, Vgontzas AN, Fernandez-Mendoza J, Bixler EO. Obstructive sleep apnea and the metabolic syndrome: the road to clinically-meaningful phenotyping, improved prognosis, and personalized treatment. Sleep Med Rev 2018;42:211-9.

7. Liu L, Kang R, Zhao S, Zhang T, Zhu W, Li E, et al. Sexual dysfunction in patients with obstructive sleep apnea: a systematic review and metaanalysis. J Sex Med 2015;12:1992-2003.

8. Ryan CF. Sleep ·9: an approach to treatment of obstructive sleep ap- 
noea/hypopnoea syndrome including upper airway surgery. Thorax 2005;60:595-604.

9. Zinchuk AV, Gentry MJ, Concato J, Yaggi HK. Phenotypes in obstructive sleep apnea: a definition, examples and evolution of approaches. Sleep Med Rev 2017;35:113-23.

10. Eckert DJ. Phenotypic approaches to obstructive sleep apnoea - New pathways for targeted therapy. Sleep Med Rev 2018;37:45-59.

11. Gottlieb DJ, Punjabi NM. Diagnosis and management of obstructive sleep apnea: a review. JAMA 2020;323:1389-400.

12. Gay P, Weaver T, Loube D, Iber C. Evaluation of positive airway pressure treatment for sleep related breathing disorders in adults. Sleep 2006; 29:381-401.

13. Kushida CA, Littner MR, Hirshkowitz M, Morgenthaler TI, Alessi CA, Bailey D, et al. Practice parameters for the use of continuous and bilevel positive airway pressure devices to treat adult patients with sleeprelated breathing disorders. Sleep 2006;29:375-80.

14. Sullivan CE, Issa FG, Berthon-Jones M, Eves L. Reversal of obstructive sleep apnoea by continuous positive airway pressure applied through the nares. Lancet 1981;1:862-5.

15. Kushida CA, Chediak A, Berry RB, Brown LK, Gozal D, Iber C, et al. Clinical guidelines for the manual titration of positive airway pressure in patients with obstructive sleep apnea. J Clin Sleep Med 2008;4:15771.

16. Kakkar RK, Berry RB. Positive airway pressure treatment for obstructive sleep apnea. Chest 2007;132:1057-72.

17. Hardinge FM, Pitson DJ, Stradling JR. Use of the Epworth Sleepiness Scale to demonstrate response to treatment with nasal continuous positive airways pressure in patients with obstructive sleep apnoea. Respir Med 1995;89:617-20.

18. Meslier N, Lebrun T, Grillier-Lanoir V, Rolland N, Henderick C, Sailly JC, et al. A French survey of 3,225 patients treated with CPAP for obstructive sleep apnoea: benefits, tolerance, compliance and quality of life. Eur Respir J 1998;12:185-92.

19. Dimsdale JE, Loredo JS, Profant J. Effect of continuous positive airway pressure on blood pressure: a placebo trial. Hypertension 2000;35(1 Pt 1): 144-7.

20. Patil SP, Ayappa IA, Caples SM, Kimoff RJ, Patel SR, Harrod CG. Treatment of adult obstructive sleep apnea with positive airway pressure: an American Academy of Sleep Medicine Clinical Practice Guideline. J Clin Sleep Med 2019;15:335-43.

21. Findley L, Smith C, Hooper J, Dineen M, Suratt PM. Treatment with nasal CPAP decreases automobile accidents in patients with sleep apnea. Am J Respir Crit Care Med 2000;161(3 Pt 1):857-9.

22. Engleman HM, Wild MR. Improving CPAP use by patients with the sleep apnoea/hypopnoea syndrome (SAHS). Sleep Med Rev 2003;7:8199.

23. Kalan A, Kenyon GS, Seemungal TA, Wedzicha JA. Adverse effects of nasal continuous positive airway pressure therapy in sleep apnoea syndrome. J Laryngol Otol 1999;113:888-92.

24. Schmidt-Nowara W, Lowe A, Wiegand L, Cartwright R, Perez-Guerra F, Menn S. Oral appliances for the treatment of snoring and obstructive sleep apnea: a review. Sleep 1995;18:501-10.

25. Kushida CA, Morgenthaler TI, Littner MR, Alessi CA, Bailey D, Coleman J Jr, et al. Practice parameters for the treatment of snoring and obstructive sleep apnea with oral appliances: an update for 2005. Sleep 2006;29:240-3.

26. Sutherland K, Vanderveken OM, Tsuda H, Marklund M, Gagnadoux F, Kushida CA, et al. Oral appliance treatment for obstructive sleep apnea: an update. J Clin Sleep Med 2014;10:215-27.

27. Ramar K, Dort LC, Katz SG, Lettieri CJ, Harrod CG, Thomas SM, et al. Clinical practice guideline for the treatment of obstructive sleep apnea and snoring with oral appliance therapy: an update for 2015. J Clin Sleep Med 2015;11:773-827.

28. Chan AS, Lee RW, Cistulli PA. Dental appliance treatment for obstructive sleep apnea. Chest 2007;132:693-9.
29. Ng AT, Gotsopoulos H, Qian J, Cistulli PA. Effect of oral appliance therapy on upper airway collapsibility in obstructive sleep apnea. Am J Respir Crit Care Med 2003;168:238-41.

30. Cunha TCA, Guimarães TM, Schultz TCB, Almeida FR, Cunha TM, Simamoto PC Junior, et al. Predictors of success for mandibular repositioning appliance in obstructive sleep apnea syndrome. Braz Oral Res 2017;31:e37.

31. Gotsopoulos H, Chen C, Qian J, Cistulli PA. Oral appliance therapy improves symptoms in obstructive sleep apnea: a randomized, controlled trial. Am J Respir Crit Care Med 2002;166:743-8.

32. Gotsopoulos H, Kelly JJ, Cistulli PA. Oral appliance therapy reduces blood pressure in obstructive sleep apnea: a randomized, controlled trial. Sleep 2004;27:934-41.

33. de Vries GE, Wijkstra PJ, Houwerzijl EJ, Kerstjens HAM, Hoekema A. Cardiovascular effects of oral appliance therapy in obstructive sleep apnea: a systematic review and meta-analysis. Sleep Med Rev 2018; 40:55-68.

34. Martins OFM, Chaves Junior CM, Rossi RRP, Cunali PA, Dal-Fabbro C, Bittencourt L. Side effects of mandibular advancement splints for the treatment of snoring and obstructive sleep apnea: a systematic review. Dental Press J Orthod 2018;23:45-54.

35. Caples SM, Rowley JA, Prinsell JR, Pallanch JF, Elamin MB, Katz SG, et al. Surgical modifications of the upper airway for obstructive sleep apnea in adults: a systematic review and meta-analysis. Sleep 2010;33: 1396-407.

36. Aurora RN, Casey KR, Kristo D, Auerbach S, Bista SR, Chowdhuri S, et al. Practice parameters for the surgical modifications of the upper airway for obstructive sleep apnea in adults. Sleep 2010;33:1408-13.

37. Wu J, Zhao G, Li Y, Zang H, Wang T, Wang D, et al. Apnea-hypopnea index decreased significantly after nasal surgery for obstructive sleep apnea: a meta-analysis. Medicine (Baltimore) 2017;96:e6008.

38. Choi JH, Kim EJ, Kim YS, Kim TH, Choi J, Kwon SY, et al. Effectiveness of nasal surgery alone on sleep quality, architecture, position, and sleep-disordered breathing in obstructive sleep apnea syndrome with nasal obstruction. Am J Rhinol Allergy 2011;25:338-41.

39. Li HY, Wang PC, Chen YP, Lee LA, Fang TJ, Lin HC. Critical appraisal and meta-analysis of nasal surgery for obstructive sleep apnea. Am J Rhinol Allergy 2011;25:45-9.

40. Camacho M, Riaz M, Capasso R, Ruoff CM, Guilleminault C, Kushida $\mathrm{CA}$, et al. The effect of nasal surgery on continuous positive airway pressure device use and therapeutic treatment pressures: a systematic review and meta-analysis. Sleep 2015;38:279-86.

41. Sher AE, Schechtman KB, Piccirillo JF. The efficacy of surgical modifications of the upper airway in adults with obstructive sleep apnea syndrome. Sleep 1996;19:156-77.

42. Choi JH, Cho SH, Kim SN, Suh JD, Cho JH. Predicting outcomes after uvulopalatopharyngoplasty for adult obstructive sleep apnea: a metaanalysis. Otolaryngol Head Neck Surg 2016;155:904-13.

43. Mulholland GB, Jeffery CC, Ziai H, Hans V, Seikaly H, Pang KP, et al. Multilevel palate and tongue base surgical treatment of obstructive sleep apnea: a systematic review and meta-analysis. Laryngoscope 2019;129: 1712-21.

44. Miller SC, Nguyen SA, Ong AA, Gillespie MB. Transoral robotic base of tongue reduction for obstructive sleep apnea: a systematic review and meta-analysis. Laryngoscope 2017;127:258-65.

45. Holty JE, Guilleminault C. Maxillomandibular advancement for the treatment of obstructive sleep apnea: a systematic review and metaanalysis. Sleep Med Rev 2010;14:287-97.

46. Zaghi S, Holty JE, Certal V, Abdullatif J, Guilleminault C, Powell NB, et al. Maxillomandibular advancement for treatment of obstructive sleep apnea: a meta-analysis. JAMA Otolaryngol Head Neck Surg 2016; 142:58-66.

47. Strollo PJ Jr, Soose RJ, Maurer JT, de Vries N, Cornelius J, Froymovich $\mathrm{O}$, et al. Upper-airway stimulation for obstructive sleep apnea. $N$ Engl J Med 2014;370:139-49. 
48. Costantino A, Rinaldi V, Moffa A, Luccarelli V, Bressi F, Cassano M, et al. Hypoglossal nerve stimulation long-term clinical outcomes: a systematic review and meta-analysis. Sleep Breath 2020;24:399-411.

49. Choi JH, Thomas RJ, Suh SY, Park IH, Kim TH, Lee SH, et al. Sleep quality change after upper airway surgery in obstructive sleep apnea: electrocardiogram-based cardiopulmonary coupling analysis. Laryngoscope 2015;125:1737-42.

50. Haraldsson PO, Carenfelt C, Lysdahl M, Tingvall C. Does uvulopalatopharyngoplasty inhibit automobile accidents? Laryngoscope 1995; 105:657-61.

51. Weaver EM, Maynard C, Yueh B. Survival of veterans with sleep apnea: continuous positive airway pressure versus surgery. Otolaryngol Head Neck Surg 2004;130:659-65.

52. Kezirian EJ, Weaver EM, Yueh B, Deyo RA, Khuri SF, Daley J, et al. Incidence of serious complications after uvulopalatopharyngoplasty. $\mathrm{La}$ ryngoscope 2004;114:450-3.

53. Choi JH, Lee SH, Cho JH, Kim SW, Cho KS, Koo SK, et al. Five-year subjective outcomes of obstructive sleep apnea surgery: a multiinstitutional study. Clin Exp Otorhinolaryngol 2015;8:370-5.

54. Morgenthaler TI, Kapen S, Lee-Chiong T, Alessi C, Boehlecke B, Brown T, et al. Practice parameters for the medical therapy of obstructive sleep apnea. Sleep 2006;29:1031-5.

55. Tuomilehto H, Seppä J, Uusitupa M. Obesity and obstructive sleep ap-
nea--Clinical significance of weight loss. Sleep Med Rev 2013;17:321-9. 56. Peppard PE, Young T, Palta M, Dempsey J, Skatrud J. Longitudinal study of moderate weight change and sleep-disordered breathing. JAMA 2000;284:3015-21.

57. SAGES Guidelines Committee. SAGES guideline for clinical application of laparoscopic bariatric surgery. Surg Endosc 2008;22:2281-300.

58. Cartwright RD. Effect of sleep position on sleep apnea severity. Sleep 1984;7:110-4

59. Oksenberg A, Silverberg DS. The effect of body posture on sleep-related breathing disorders: facts and therapeutic implications. Sleep Med Rev 1998;2:139-62.

60. Lee E, Choi JH, Lee B, Jung JH, Seon SW, Lee S, et al. Effect of positional therapy on patients with obstructive sleep apnea: meta-analysis. J Rhinol 2017;24:94-103.

61. Stuck BA, Maurer JT. Airway evaluation in obstructive sleep apnea. Sleep Med Rev 2008;12:411-36.

62. Togeiro SM, Chaves CM Jr, Palombini L, Tufik S, Hora F, Nery LE. Evaluation of the upper airway in obstructive sleep apnoea. Indian J Med Res 2010;131:230-5.

63. Berry RB, Quan SF, Abreu AR, Bibbs ML, DelRosso L, Harding SM, et al. The AASM manual for the scoring of sleep and associated events: rules, terminology and technical specifications, version 2.6. Darien, CT: American Academy of Sleep Medicine 2020. 